\title{
Optimization of Draft and Twist Values for Improvement of Breaking Strength and Elongation Properties of Dual-Core Yarns
}

\author{
Sümeyye ÜSTÜNTAĞ (D) 0000-0002-2625-4063
}

Faculty of Engineering, Department of Textile Engineering, Erciyes University, 38039, Kayseri, Turkey

Corresponding Author: Sümeyye Üstüntağ, sumeyyeustuntag@erciyes.edu.tr

\begin{abstract}
Dual-core yarns, which are developed to have high elasticity and strength properties at the same time in the yarn structure, have been the focus of interest in yarn sector. Considering the purpose of developing dual-core yarns, it is obvious that the breaking strength and elongation performances expected from these yarns are very important. In this paper, the twist coefficient and PET (Polyethylene terephthalate)/Elastane draft ratios of dual-core yarns were optimized by Taguchi Method for improved of breaking strength and elongation performance. The signal to noise ratio (SNR) was calculated for each output and optimum levels were determined over these ratios. As a result of the study, it was determined that PET draft was the most effective parameter for both outputs. Considering the individual optimum levels determined for each output, common factor-level combinations covering both outputs were determined. Consequently, optimal common combination for the multi-performances was found as 4.2 twist coefficient, 1.15 PET draft ratio and 3.8 elastane ratio.
\end{abstract}

\section{ARTICLE HISTORY}

Received: 26.03.2021

Accepted: 17.08.2021

\section{KEYWORDS}

Dual-core yarn, Elastane draft ratio, PET draft ratio, Twist coefficient, Breaking elongation, Breaking strength

\section{INTRODUCTION}

Elastic materials that impart stretch and recovery capability to fabrics or garments are widely used for fashionable and functional apparel products such as denim fabrics, medical textiles and sportswear [1]. Core-spun yarn spinning technology is a widely preferred method for placing elastic materials in fabric structure, especially in the denim industry. The elastic core-spun yarn which is a multicomponent textile structure, consists of elastane core (lycra $\AA$, creora $\AA$ etc.) covered by natural or man-made fibers with a certain twist. The elastic core part ensures the yarn to have better stretch and recovery properties; besides, the sheath fibers improve physical and comfort properties of fabrics. In addition to the use of elastic core-spun yarn, core-spun yarns containing PET, PA, PBT and T400® filament are often preferred in order to enhance some characteristics of fabric i.e. mechanical and functional properties. Lately, dual-core yarns have been developed in order to produce fabrics having better recovering, durability and lower shrinkage as compared to the traditional singlecore yarns containing only elastane in the core and cotton in the sheath. The dual core-spun yarns are composed of two core components; filament (PET, PA etc.) and elastane or semi-elastic core [2, 3]. Dual-core yarns can be manufactured on modified conventional ring spinning machine in two different methods. In the first method, previously combined two core yarns are fed simultaneously, whereas in the second method, two core yarns are fed separately into the center of sheath fiber bundle. Dual-core yarns produced with the first method are called as pre-treated dual-core yarns (PDC) while the yarns

To cite this article: Üstüntağ, S. 2021. Optimization of draft and twist values for improvement of breaking strength and elongation properties of dual-core yarns. Tekstil ve Konfeksiyon, 31(3), 220-227. 
obtained with the second method are named as dual-core (DC) yarns.

In recent years, dual-core yarns are highly preferred for high quality fabrics and therefore, works on dual-core yarns are increasing, day by day. Aydoğdu and Yılmaz studied the effects of dual-core yarn production parameters (different sheath fiber types, yarn counts, and core filament linear densities) on some yarn and fabric properties. They found that dual-core yarns with cotton sheath fibres had significantly higher yarn unevenness, hairiness, thick places, neps, and lower tenacity and breaking elongation values, when compared to cotton/Tencel fibre and viscose sheath fibers [4]. Erbil et al. investigated the structure and properties of plain, elastane containing, and elastane + filament containing hybrid yarns, produced by using cotton as sheath fibers. They found that the elastic behaviour of dual-core yarns was higher when compared to elastane core and $100 \%$ carded cotton yarns [5]. Ute worked on influence of the weft density and weft yarn type on mechanical and dimensional properties of denim fabrics for dual-core and core-spun. At the end of the study, it was determined that growth values of the fabrics with elastic core-spun weft yarns were generally higher than the growth values the fabrics with elastic dual-core weft yarns [6]. Ertaş at al. evaluated some properties of denim fabrics produced with different weft densities by using elastane containing dualcore yarns. They found that as weft density increased, permanent elongation decreased [7]. Babaarslan at al. investigated the air permeability of denim fabrics made from dual-core spun weft yarns with different filament fineness and elastane draft, by comparing them with PET filament core-spun yarns and $100 \%$ cotton yarns. They revealed that the elastane draft ratio had a significant effect on the denim fabric air permeability whereas filament fineness had no effect on air permeability [8]. Jabbar at al. studied the effects of PET and elastane linear density on the physical and mechanical properties of dual-core cotton yarns. They revealed that yarn tenacity, elongation, uniformity, and hairiness was significantly affected by the linear densities of both the PET and elastane filaments in the core [2]. Türksoy and Yildırım investigated the influence of some production parameters such as twist level, wool draft and elastane draft on the properties of dual-core yarns containing wool/elastane. The results indicated that the twist level was significantly effective parameter for the unevenness, hairiness, tenacity and elongation values of dual-core yarns. In addition, it was also observed that variation of elastane draft level affected tenacity and elongation values of dual-core yarns [9].

Breaking strength and elongation are among the most important and widely measured property of core-spun yarns. Yarn strength and elongation, like other yarn properties, is mainly influenced by fibre properties, yarn twist, and yarn count. Since these properties are strongly correlated with loom efficiency and usage performance, it would be very useful to estimate the optimum yarn strength and elongation, accurately. When we look at the literature in general, the effects of the production parameters of dualcore yarns on the yarn strength and elongation were examined separately. While examining the factors affecting the strength and elongation of multicomponent yarns, considering all outputs together will provide more accurate results. In this study, firstly, the optimum draft and twist values of dual-core yarns were determined separately for maximum breaking strength and elongation value. Then, common optimum factor levels were determined for both outputs. Taguchi method was used for the analysis of input factors selected and the optimization of this factors.

\subsection{Taguchi Method}

The full factorial design considers all possible combinations of a certain set of factors. As most of the industrial experiments normally include a considerable number of factors, a full factorial design results in a great number of experiments. Contrary to the full factorial design, Taguchi method provides the utility in terms of cost and time by reducing the number of experiments [10]. The Taguchi method is a statistical off-line quality control method that purposes to minimize product or process variation at the design phase. In Taguchi method, there are three design stages, which are system, parameter and tolerance designs. In system design, scientific and engineering knowledge is utilized to detect the basic arrangement of the process. With the parameter design, the settings that minimize the variation change in performance characteristics and adjust its mean to an ideal value are determined. Parameter design is a methodology used to determine the best tolerances for parameters, between system design and tolerance design [11].

The orthogonal array (OA) and the signal to noise ratio (SNR) are two important tools utilized in the Taguchi method [12]. Orthogonal arrays are utilized to organize the factors that influence the process and the levels where they should vary [13]. OA is a matrix of numbers arranged in rows and columns. Each row represents the level of factors in each run and each column represents a specific level for a factor that can be changed for each run [12].

The general purpose of the Taguchi design is to detect factor levels that maximize the SNR is a measure of the performance variability of processes in the presence of noise factors. In that, $\mathrm{S}$ stands for mean and that is called signal and also $\mathrm{N}$ stands for standard deviation and that is called noise [11]. The higher the $\mathrm{S} / \mathrm{N}$ ratio, the better the quality; in general, the $\mathrm{S} / \mathrm{N}$ ratio is classified into three modes where smaller is better, nominal is better or larger is better [10].

Nominal-the-better: 
$S / N=-10 \log \left[\frac{1}{n} \sum_{i=1}^{n}\left(y_{i}-m\right)^{2}\right]=-10 \log \left[(\bar{y}-m)^{2}+S^{2}\right]$

Larger-the-better

$S / N=-10 \log \left[\frac{1}{n} \sum_{i=1}^{n} \frac{1}{y_{i}^{2}}\right]$

Smaller-the-better

$S / N=-10 \log \left[\frac{1}{n} \sum_{i=1}^{n} y_{i}^{2}\right]=-10 \log \left(\bar{y}^{2}\right)$

where S denotes the standard deviation; yi the data obtained from experiments; $n$ represents the number of experiments.

\section{MATERIAL AND METHOD}

\subsection{Design of experiment}

The selection of control factors is the most important step in the Taguchi method. By controlling these factors, the standard deviation of the process can be reduced. In this study, three factors, namely, twist coefficient, PET draft ratio and elastane draft ratio were determined as the parameters affecting breaking strength and elongation of dual-core yarns. The range of parameters was determined from the preliminary experiments. In order to examine the non-linear effect of process parameters, each parameter was examined at three levels. The identified process parameters and their levels are summarized in Table 1.

Table 1. The factors and their levels

\begin{tabular}{cccc}
\hline \multirow{2}{*}{ Levels } & \multicolumn{3}{c}{ Factors } \\
\cline { 2 - 4 } & $\begin{array}{c}\text { Twist } \\
\text { coefficient }\end{array}$ & $\begin{array}{c}\text { PET } \\
\text { draft ratio }\end{array}$ & $\begin{array}{c}\text { Elastane } \\
\text { draft ratio }\end{array}$ \\
\hline 1 & 3.9 & 1.05 & 3.4 \\
2 & 4.2 & 1.10 & 3.6 \\
3 & 4.5 & 1.15 & 3.8 \\
\hline
\end{tabular}

The selection of orthogonal matrix is the step after the determination of factors and levels. The orthogonal array allows for the gathering of the requisite data to set which factors affect product quality the most, with a minimum amount of trial, thus saving time and resources [14]. In this paper, L9 orthogonal array was chosen to determine experimental plan because it is the most suitable for the conditions being investigated; three factors with three levels. Factor levels were selected from the operable values. Minitab 16.0 software package was utilized for obtaining the orthogonal matrix given in Table 2. This matrix provides to adjust the group specification during sample production. According to orthogonal matrix, experimental layout given in Table 2 was arranged.

\subsection{Preparation of test specimens}

At this stage, dual-core yarns were produced depending on the experimental layout. Nine cotton-wrapped dual-core yarn samples were prepared using different twist coefficient, draft ratios of elastane and PET filaments as input variables. $100 \% \mathrm{ABD}$ cotton fibers were used to produce yarn samples and the cotton fibre specifications (Table 3) were measured by Uster ${ }^{\circledR}$ High Volume Instrument (HVI 1000). The cotton fibers were processed through blow room line (Trützschler Blendomat, Trützschler BOA, Trützschler AFC, Trützschler mixer, Trützschler CVT-4 and Trützschler DX), carding machine (Trützschler DK803), drawing frame (Rieter RSB D45), roving frame (Marzoli FT7D), ring frame (Marzoli MDS1) with special core filament insertion device and winding machine (Sauro) to produce dual-core yarn of linear density $\mathrm{Ne}$ 18.0. The schematic representation of dual-core yarn production is given in Fig. 1.

Table 2. The orthogonal matrix and the experimental layout

\begin{tabular}{|c|c|c|c|c|c|c|}
\hline \multirow{2}{*}{$\begin{array}{c}\text { Experiment } \\
\text { no. }\end{array}$} & \multicolumn{3}{|c|}{$\begin{array}{l}\text { Factors and } \\
\text { their levels }\end{array}$} & \multicolumn{3}{|c|}{ Experimental layout } \\
\hline & A & B & $\mathrm{C}$ & $\begin{array}{c}\text { Twist } \\
\text { coefficient }\end{array}$ & $\begin{array}{c}\text { PET } \\
\text { draft ratio }\end{array}$ & $\begin{array}{l}\text { Elastane } \\
\text { draft ratio }\end{array}$ \\
\hline 1 & 1 & 1 & 1 & 3.9 & 1.05 & 3.4 \\
\hline 2 & 1 & 2 & 2 & 3.9 & 1.10 & 3.6 \\
\hline 3 & 1 & 3 & 3 & 3.9 & 1.15 & 3.8 \\
\hline 4 & 2 & 1 & 2 & 4.2 & 1.05 & 3.6 \\
\hline 5 & 2 & 2 & 3 & 4.2 & 1.10 & 3.8 \\
\hline 6 & 2 & 3 & 1 & 4.2 & 1.15 & 3.4 \\
\hline 7 & 3 & 1 & 3 & 4.5 & 1.05 & 3.8 \\
\hline 8 & 3 & 2 & 1 & 4.5 & 1.10 & 3.4 \\
\hline 9 & 3 & 3 & 2 & 4.5 & 1.15 & 3.6 \\
\hline
\end{tabular}

Table 3. The cotton fibre specifications

\begin{tabular}{lll}
\hline Specifications & & Values \\
\cline { 1 - 1 } Spinning Consistency Index & & 112 \\
Microner index & & 4.5 \\
Maturity index & & 0.87 \\
UHML- fibre length, mm & & 28.19 \\
UI- Uniformity index, \% & 80.2 \\
Short Fiber, \% & 8.2 \\
Fibre strength, g/tex & 28.5 \\
Fibre elongation, \% & 5.8 \\
\hline
\end{tabular}




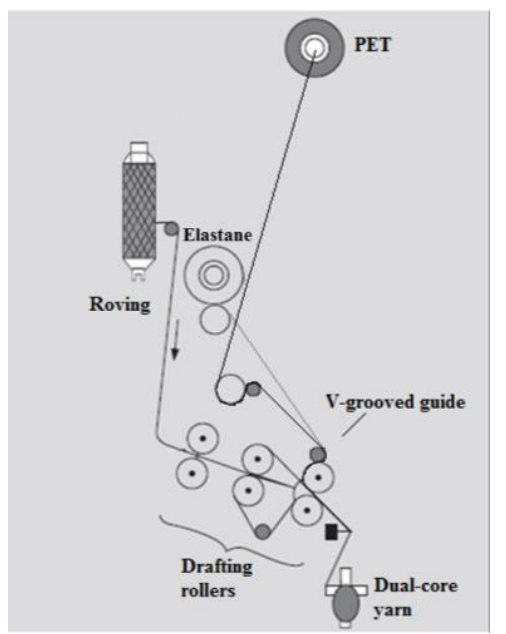

Figure 1. The schematic representation of dual-core yarn

50 denier PET (36f) and 78 dtex Lycra ${ }^{\circledR}$ filaments were used as the core components for dual-core yarns. In dualcore spun yarn production, the core components of PET and Lycra filaments were fed to the nip point of the front rollers by means of $\mathrm{V}$-grooved guide roller. PET and Lycra elastane core filaments were covered by cotton on conventional ring spinning machine with 760 turns $/ \mathrm{m}$.

\subsection{Yarn Testing}

All dual-core yarn samples were conditioned at $20 \pm 1{ }^{\circ} \mathrm{C}$ and $65 \pm 2 \%$ relative humidity according to ISO 139 before the test. The quality specifications of the sample yarns (unevenness, hairiness, thin/thick place, Neps) were tested on Uster Tester 5 at $400 \mathrm{~m} / \mathrm{min}$ test speed. Mechanical properties (breaking strength and elongation) of the yarns were measured on Uster Tensojet tester at $500 \mathrm{~m} / \mathrm{min}$ in accordance with ISO 2062 standard.

\subsection{Analysis Method}

Test results were analyzed by the parameter design of the Taguchi method using Minitab 16 statistical software. After testing the yarns produced according to the experimental design, the following steps were used to optimize process with multiple performance characteristics: (1) analysis of the experimental results using the $\mathrm{S} / \mathrm{N}$ and ANOVA analyses; (2) selection of the optimal levels of design parameters; (3) prediction of output results through the optimal design parameters; and (4) calculation of improving rate using optimum factor levels.

\section{RESULTS AND DISCUSSION}

Because the $\mathrm{S} / \mathrm{N}$ ratio can reflect both the mean and variation of the quality characteristics, the Taguchi method uses the $\mathrm{S} / \mathrm{N}$ ratio instead of the mean value to interpret experimental results [15]. In this paper, the performance statistics of the larger-the-better (Eq. 2) was used to define the optimal process conditions of dual-core yarns for both outputs. Because, the high strength and elongation at break of the yarns are known to affect the production efficiency of denim fabrics positively. The orthogonal matrix, the quality parameters and $\mathrm{S} / \mathrm{N}$ ratios for breaking strength and elongation of the dual-core yarns are given in Table 4 .

Taguchi method presents the response table and response graph for each output. The table and the graph show mean of $\mathrm{S} / \mathrm{N}$ ratios at different levels for each factor. The factor levels corresponding to the maximum mean $\mathrm{S} / \mathrm{N}$ ratio are selected as the optimum levels. In response table, the delta value is calculated by subtracting the largest value from the lowest from among the values in each column. A higher delta value amounts that the difference at the selected level for a given factor is highly pronounced. Further, rank value in the response table shows the influence degree of factors on the examined output.

Fig. 2 illustrates the main effects plot for $\mathrm{S} / \mathrm{N}$ of the breaking strength output. It is seen that the optimum levels of the production parameters for breaking strength are 4.2 twist coefficient, 1.1 PET draft ratio and 3.6 elastane draft ratio (A2B2C2). In other words, the dual-core yarns produced at intermediate levels have been found to show higher breaking strength values than others. As can be seen from Table 5, the most effective input parameter is PET draft ratio (B). When the PET draft value is 1.1 from 1.05 , it is seen that there is a significant increase in the strength value of the yarn. However, when the PET draft value is increased to 1.15 , a slight decrease is observed in the strength value of dual-core yarns. For core-spun yarns containing elastane, it has been proven in many studies that as the core filament is getting finer, the number of sheath filaments increases and thus its contribution to strength increases [16-19]. However, PET core is generally used to prevent the bagging problem in the dual-core yarn structure as well as to increase the decreasing

Table 4. The orthogonal matrix, the quality parameters and $\mathrm{S} / \mathrm{N}$ ratios of the dual-core yarns

\begin{tabular}{ccccccccccc}
\hline No. & A & B & C & CVm & IPI & H & $\begin{array}{c}\text { B. Strength } \\
\text { cN/tex }\end{array}$ & $\begin{array}{c}\text { B. Strength } \\
\text { S/N ratio, dB }\end{array}$ & $\begin{array}{c}\text { B. Elongation } \\
\%\end{array}$ & $\begin{array}{c}\text { B. Elongation } \\
\text { S/N ratio, dB }\end{array}$ \\
\hline 1 & 1 & 1 & 1 & 13.07 & 229.50 & 7.36 & 13.20 & 22.38 & 9.17 & 19.24 \\
2 & 1 & 2 & 2 & 13.20 & 207.50 & 7.27 & 15.42 & 23.75 & 12.21 & 21.72 \\
3 & 1 & 3 & 3 & 13.76 & 261.00 & 7.05 & 14.56 & 23.24 & 14.92 & 23.46 \\
4 & 2 & 1 & 2 & 13.31 & 215.50 & 7.31 & 14.30 & 23.03 & 11.32 & 20.87 \\
5 & 2 & 2 & 3 & 13.24 & 183.00 & 7.48 & 14.92 & 23.37 & 12.46 & 21.89 \\
6 & 2 & 3 & 1 & 13.84 & 288.50 & 7.63 & 15.19 & 23.63 & 15.07 & 23.56 \\
7 & 3 & 1 & 3 & 13.28 & 226.00 & 6.97 & 13.48 & 22.58 & 9.37 & 19.41 \\
8 & 3 & 2 & 1 & 13.37 & 225.50 & 7.02 & 15.48 & 23.78 & 11.59 & 21.27 \\
9 & 3 & 3 & 2 & 13.69 & 250.50 & 7.41 & 15.28 & 23.62 & 14.82 & 23.41 \\
\hline
\end{tabular}




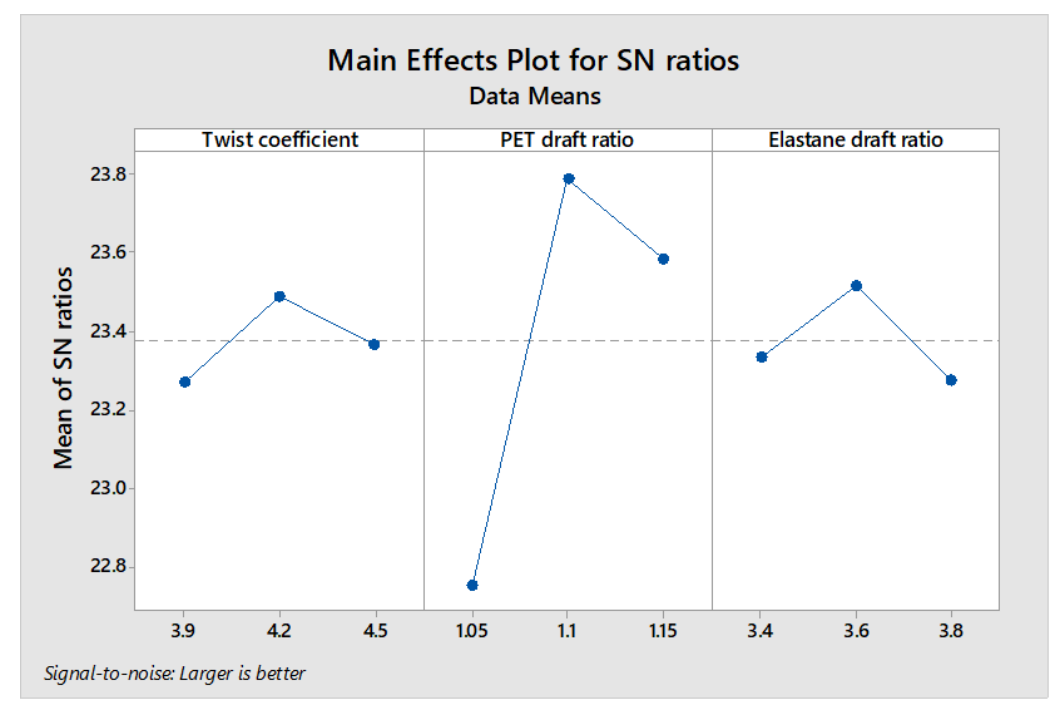

Figure 2. Main effects plot for $\mathrm{S} / \mathrm{N}$ of the breaking strength output

Table 5. Response Table for the $\mathrm{S} / \mathrm{N}$ ratio of the breaking strength output

\begin{tabular}{ccccccc}
\hline \multirow{2}{*}{ Factors } & \multicolumn{3}{c}{ Average S/N, dB } & & & \\
\cline { 2 - 4 } \cline { 6 - 7 } & Level 1 & Level 2 & Level 3 & & Delta & Rank \\
\hline A & 23.27 & $23.49^{*}$ & 23.37 & & 0.22 & 3 \\
B & 22.75 & $23.79^{*}$ & 23.59 & & 1.04 & 1 \\
C & 23.34 & $23.52^{*}$ & 23.28 & & 0.24 & 2 \\
\hline
\end{tabular}

Table 6. ANOVA Table for $\mathrm{S} / \mathrm{N}$ ratio of the breaking strength output

\begin{tabular}{ccccccc}
\hline Factor & df & $\begin{array}{c}\text { Sum of } \\
\text { squares }\end{array}$ & Mean square & F-value & P & $\begin{array}{c}\text { Percentage } \\
\text { contribution }(\%)\end{array}$ \\
\hline A & 2 & 0.07008 & 0.035042 & 9.86 & 0.092 & 3.52 \\
B & 2 & 1.82156 & 0.910779 & 256.23 & 0.004 & 91.44 \\
C & 2 & 0.09341 & 0.046704 & 13.14 & 0.071 & 4.69 \\
Residual & 2 & 0.00711 & 0.003555 & & & 0.36 \\
Total & 8 & 1.99216 & & & & 1.00 \\
\hline
\end{tabular}

strength with the presence of elastane in the structure. Therefore, it is clear that the sheath fibers and PET filament greatly effect of strength the dual-core yarns. Depending on the increase of draft values in the study, nonlinear strength tendency may be related to this situation. It is thought that the sheath fiber number in the cross section and the molecular chain structure of the PET filament affect the strength of produced dual-core yarns with 1.1 PET draft value at the same time.

The statistically significant input parameters are determined by conducting ANOVA test. Contribution value which is a percentage value for the process effect is calculated using the sum of squares values in the ANOVA table. The bigger this value on the output of that parameter is understood to be effective at that rate. As shown in Table 6, only the PET draft ratio is statistically effective on the breaking strength value and the contribution rate of this input parameter is calculated as $91.44 \%$. As can be understood from this result, the breaking strength value of the dual-core yarns varies greatly with the PET draft ratio. In addition, the contribution rates of the twist coefficient and elastane draft ratio are $3.52 \%$ and $4.69 \%$, respectively. It is estimated that the low contribution of variations of these factors to the strength is due to the presence of a durable component such as PET in the yarn structure. With this result, it can be concluded that the selected ranges for the elastane draft ratio and twist coefficient are suitable values for the breaking strength values of dual-core yarns and all these values can be used depending on the other properties expected from the yarns upon customer request. Furthermore, it is seen that the error contribution due to interaction effect is around $0.36 \%$. This ratio is quite small and therefore, the factors can be evaluated independently. 


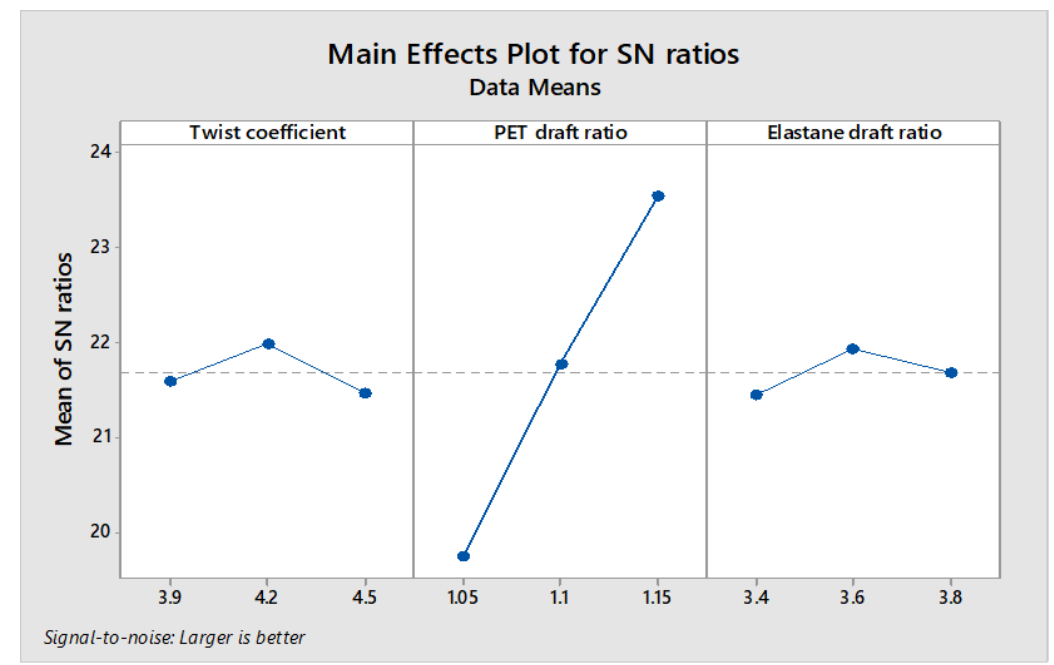

Figure 3. Main effects plot for $\mathrm{S} / \mathrm{N}$ of the breaking elongation output

Table 7. Response Table for the $\mathrm{S} / \mathrm{N}$ ratio of the breaking elongation output

\begin{tabular}{cccccc}
\hline \multirow{2}{*}{ Factors } & \multicolumn{5}{c}{ Average S/N, dB } \\
\cline { 2 - 6 } & Level 1 & Level 2 & Level 3 & Delta & Rank \\
\hline A & 21.59 & $21.98^{*}$ & 21.46 & 0.52 & 2 \\
B & 19.73 & 21.76 & $23.54 *$ & 3.81 & 1 \\
C & 21.44 & $21.92^{*}$ & 21.67 & 0.48 & 3 \\
\hline
\end{tabular}

As can be seen from Figure 3 and Table 7, the optimum levels of the production parameters for breaking elongation are 4.2 twist coefficient, 1.15 PET draft ratio and 3.6 elastane draft ratio (A2B3C2). Depending on Table 7, it is seen that the most effective input parameter is PET draft ratio (B) and as the PET draft ratio increases, the breaking elongation value of dual-core yarns increases. When the core-spun containing filament is subjected to a force, the fibers of both components will be elongated as the force increases, until the fibers with smaller elongation break and so transfer the entire load to other fibers [20]. As can be understood, the proportion of sheath cotton fibers in the yarn cross-section mainly affects the elongation time and thus the breaking elongation value. Basically, with the increasing the draft ratio, PET\% ratio in the yarn structure decreases, which means more number of sheath fibers. In this case, the contribution of staple fibers to strength and elongation is thought to increase [21]. However, this situation was not observed for the elastane filament draft ratio. From this result, it is understood that the presence of PET filament with higher strength than elastane in the structure makes the effect of the draft change of the elastane filament on the strength and elongation values of the yarn insignificant.

Similar to the breaking strength results, only PET draft ratio is found statistically significant on the breaking elongation values of dual-core yarns and the contribution rate is 96.32\% (Table 8). At the same time, the effect of the other two factors is very low. Furthermore, it is clear that the ANOVA test has resulted in around $1.54 \%$ of error contribution owing to interaction effect.

\subsection{Optimization}

The arrays corresponding to optimum factor levels determined by Taguchi method may not be available in experimental design. In such cases, the performance values corresponding to optimum factor levels can be predicted by utilizing the balanced characteristic of orthogonal arrays [22]. Since the optimum factor-level combinations obtained for both outputs in the study were not included in the experimental design, the predicted $\mathrm{S} / \mathrm{N}$ ratios were calculated using Eq. 4. The predicted $\mathrm{S} / \mathrm{N}$ ratios were placed in Eq. 2, and the predicted breaking strength and elongation values were achieved.

Table 8. ANOVA Table for $\mathrm{S} / \mathrm{N}$ ratio of the breaking elongation output

\begin{tabular}{ccccccc}
\hline Factor & df & $\begin{array}{c}\text { Sum of } \\
\text { squares }\end{array}$ & Mean square & F-value & P & $\begin{array}{c}\text { Percentage contribution } \\
(\%)\end{array}$ \\
\hline A & 2 & 0.4462 & 0.2231 & 11.59 & 0.079 & 1.97 \\
B & 2 & 21.7844 & 10.8922 & 565.70 & 0.002 & 96.32 \\
C & 2 & 0.3476 & 0.1738 & 9.03 & 0.100 & 2.94 \\
Residual & 2 & 0.0385 & 0.0193 & & & 1.54 \\
Total & 8 & 22.6167 & & & & 1.00 \\
\hline
\end{tabular}




$$
\eta_{0}=\eta_{m}+\sum_{i=1}^{j}\left(\eta_{i}-\eta_{m}\right)
$$

where, $\eta_{\mathrm{m}}$ is total mean of $\mathrm{S} / \mathrm{N}$ ratio, $\mathrm{j}$ is the number of factors, and $\eta_{\mathrm{i}}$ are the multiple $\mathrm{S} / \mathrm{N}$ ratios corresponding to optimum factor levels.

Table 9 shows the $\mathrm{S} / \mathrm{N}$ ratios and results obtained according to the predicted and experimental optimal combinations. According to the experimental results given in Table 4, the highest value for the breaking strength $(15.48 \mathrm{cN} /$ tex $)$ was reached with the combination of $\mathrm{A} 3 \mathrm{~B} 2 \mathrm{C} 1$ and the $\mathrm{S} / \mathrm{N}$ ratio of this result was calculated as $23.78 \mathrm{~dB}$. As a result of the prediction made for the optimal combination obtained with $\mathrm{TM}$, the value and $\mathrm{S} / \mathrm{N}$ ratio of breaking strength were calculated as 15.98 and 24.04 , respectively. In the experimental analysis for the breaking elongation, the highest values $(15.07 \%$ and $23.56 \mathrm{~dB})$ were reached with the $\mathrm{A} 2 \mathrm{~B} 3 \mathrm{C} 1$ combination. However, it was predicted that $15.70 \%$ breaking elongation and $24.09 \mathrm{~dB}$ S/N ratio would be reached, with the combination suggested by TM. As can be seen, it is seen that there is a slightly increase in output results with the combinations obtained as a result of optimization.

The improvement rates to be seen with the predicted optimum combinations determined by TM for both outputs were calculated by Equation 5. The improvement rate is calculated from the "d" value obtained by subtracting the predicted $\mathrm{S} / \mathrm{N}$ ratio of the predicted optimum combination $\left(\mathrm{S} / \mathrm{N}_{0}\right)$ from the $\mathrm{S} / \mathrm{N}$ ratio of the experimental optimum combination $\left(\mathrm{S} / \mathrm{N}_{\mathrm{i}}\right)$ (Table 9). Through the equation given below [23], the breaking strength of dual-core yarns under predicted optimum conditions was found to be increased
1.06 times according to the experimental optimum combination. It was also observed the breaking elongation increased 1.13 times.

$$
\begin{aligned}
& d=\frac{S}{N_{i}}-\frac{S}{N_{o}}=-10 \log L_{i}-\left(-10\left(\log L_{o}\right)\right) \\
& \frac{L_{o}}{L_{i}}=10^{\frac{d}{10}}
\end{aligned}
$$

For dual-core yarns, both breaking strength and elongation properties are expected to be at ideal levels. It becomes very important to combine these effects in order to get an idea over the total optimization by making a sensible comparison of each output. First, the optimum levels for each output were determined separately. Taking into account the levels of all outputs, the combination of optimum levels was determined (Table 10). Here, coefficients $\mathrm{a}, \mathrm{b}$ and $\mathrm{c}$ symbolize the importance level of each factor and indicate the first, the second and the third effective parameter, respectively.

Table 10 shows the common optimum twist coefficient and draft ratio values for both outputs. For PET draft ratio, the alteration of $\mathrm{S} / \mathrm{N}$ ratio depending on the level ranges were examined on separate graphs for each output. $3^{\text {rd }}$ level (1.15) of PET draft ratio was selected for combination since a greater alteration was observed with the optimum level determined for the breaking elongation, compared to breaking strength. Consequently, the levels determined according to the combination of all outputs were found to be the same as the optimum levels determined for breaking

\begin{tabular}{|c|c|c|c|c|}
\hline \multirow{5}{*}{$\begin{array}{l}\text { Optimal Level } \\
\text { Results } \\
\text { S/N ratio }\end{array}$} & \multicolumn{2}{|c|}{ Experimental Optimal Combinations } & \multicolumn{2}{|c|}{ Predicted Optimal Combinations } \\
\hline & B. Strength & B. Elongation & B. Strength & B. Elongation \\
\hline & A3B2C1 & $\mathrm{A} 2 \mathrm{~B} 3 \mathrm{C} 1$ & $\mathrm{~A} 2 \mathrm{~B} 2 \mathrm{C} 2$ & $\mathrm{~A} 2 \mathrm{~B} 3 \mathrm{C} 2$ \\
\hline & 15.48 & 15.07 & 15.98 & 15.70 \\
\hline & 23.78 & 23.56 & 24.04 & 24.09 \\
\hline
\end{tabular}
elongation of dual-core yarns.

Table 9. Experimental and predicted optimal $\mathrm{S} / \mathrm{N}$ ratios and results

Table 10. The combination of optimum levels for all outputs

\begin{tabular}{lllll}
\hline & & \multicolumn{3}{c}{ Factors } \\
\cline { 3 - 5 } & & $\mathrm{A}$ & $\mathrm{B}$ & $\mathrm{C}$ \\
\hline \multirow{2}{*}{ Breaking strength } & Optimum Level & $2^{\mathrm{c}}$ & $2^{\mathrm{a}}$ & $2^{\mathrm{b}}$ \\
& Optimum Value & 4.2 & 1.1 & 3.8 \\
\hline \multirow{2}{*}{ Breaking elongation } & Optimum Level & $2^{\mathrm{b}}$ & $3^{\mathrm{a}}$ & $2^{\mathrm{c}}$ \\
& Optimum Value & 4.2 & 1.15 & 3.8 \\
\hline \multirow{2}{*}{ Combination } & Optimum Level & 2 & 3 & 2 \\
& Optimum Value & 4.2 & 1.15 & 3.8 \\
\hline
\end{tabular}

${ }^{a}$ The first effective parameter, ${ }^{b}$ The second effective parameter, ${ }^{\mathrm{c}}$ The third effective parameter 


\section{CONCLUSION}

In this paper, the twist coefficient and the draft ratios of the PET and Elastane components of dual-core yarns were optimized by Taguchi Method for improvement of their breaking elongation and strength performances. Among the factors examined for both outputs, it was determined that only PET draft ratio had a statistically significant effect. For both outputs, the optimum $\mathrm{S} / \mathrm{N}$ ratios were achieved with the median level of elastane draft ratio and twist coefficient. However, different optimum PET draft ratio levels were obtained for each output. While reaching the optimum S/N ratio with median PET draft ratio level for breaking strength, it was observed that the breaking elongation increased with the increase of PET draft ratio value. It was observed that the difference between the $\mathrm{S} / \mathrm{N}$ ratios of the breaking elongation of the dual-core yarns produced with the $2^{\text {nd }}$ level (1.1) and $3^{\text {rd }}$ level (1.15) PET draft values was bigger compared to the breaking strength. As a result, it was decided that the common optimum levels

\section{REFERENCES}

1. Hua T, Wong NS, Tang WM. 2018. Study on properties of elastic corespun yarns containing a mix of spandex and PET/PTT bi-component filament as core. Textile Research Journal 88(9) 1065-1076.

2. Jabbar A, Tariq U, Hussain T, Basit A, Hai A, Zubair M. 2020. Effect of polyester and elastane linear density on the physical and mechanical properties of dual-core-spun cotton yarns. Journal of Natural Fibers 17 (4), 463-471.

3. Babaarslan O, Sarioğlu E, Çelik Hİ, Avci ME. 2018. Denim fabrics woven with dual core-spun yarns. Engineered Fabrics. Licensee IntechOpen, 19-39.

4. Aydoğdu SH, Yilmaz D. 2020. Effect of yarn fineness and core/sheath fibre types on the physical properties of dual-core yarns and fabrics. Cellulose Chemistry and Technology 54(3-4), 381-394.

5. Erbil Y, Islam R, Babaarslan O, Sırlıbaş S. 2020. Effect of structural changes on the cotton composite yarn properties Journal of Natural Fibers, doi: 10.1080/15440478.2020.1788687@ 2020 Taylor \& Francis.

6. Ute TB. 2019. Analysis of mechanical and dimensional properties of the denim fabrics produced with double-core and core-spun weft yarns with different weft densities. The Journal of The Textile Institute 110(2), 179-185.

7. Ertaş O G, Ünal BZ, Çelik N. 2016. Analyzing the effect of the elastane-containing dual-core weft yarn density on the denim fabric performance properties. The Journal of The Text Institute 107(1), 116-126.

8. Babaarslan O, Sarioğlu E, Kaynak HK, Avcı ME. 2018, June. Air permeability analysis of denim fabrics from dual-core spun yarns. 18thAUTEX World Textile Conference (20-22), İstanbul, Turkey.

9. Turksoy HG, Yildirim N. 2018. Effect of process variables on the properties of dual-core yarns containing wool/elastane. Industria Textila 69(5), 352-356.

10. Fazeli F, Tavanai H, Hamadani AZ. 2012. Application of Taguchi and full factorial experimental design to model the color yield of cotton fabric dyed with six selected direct dyes. Journal of Engineered Fibers and Fabrics 7(3), 34-42.

11. Zeydan M. 2007. Modelling the woven fabric strength using artificial neural network and Taguchi methodologies. Inter Journal of Clothing Science and Technology 20(2), 104-118.

12. Khosla A, Kumar S, Aggarwal KK. 2006. Identification of strategy parameters for particle swarm optimizer through Taguchi method. $J$ Zhejiang Univ Science A 7(12), 1989-1994. for both outputs were 4.2 twist coefficient, 1.15 PET draft ratio and 3.8 elastane draft ratio.

The predicted maximum breaking strength and elongation values that can be reached with the optimum levels determined by TM were calculated based on the experimental results. Based on these predicted values, the expected improvement rates in both outputs were calculated thanks to the determined optimum levels. It was concluded that with the factor-level combinations determined and not included in the experimental design in the study, the breaking strength would increase 1.06 times and the breaking elongation would increase 1.13 times compared to the experimental optimum combination.

\section{Acknowledgements}

The author also wishes to express their gratitude to Çalık Denim San. Tic. A.Ş. (Malatya/Turkey) for the sample preparation and the sample testing.

13. Khanlou HM, Ang BC, Talebian S, Afifi AM, Andriyana A. 2015. Electrospinning of polymethyl methacrylate nanofibers: optimization of processing parameters using the Taguchi design of experiments. Textile Research Journal 85(4), 356-368.

14. Khan KR, Hossain MM, Sarker RC. 2015. Statistical analyses and predicting the properties of cotton/waste blended open-end rotor yarn using Taguchi OA design. International Journal of Textile Science 4(2), 27-35.

15. Gaitonde VN, Karnik SR, Davim JP. 2008. Taguchi multipleperformance characteristics optimization in drilling of medium density fibreboard (MDF) to minimize delamination using utility concept. Journal of Materials Processing Technology 196, 73-78.

16. Dhuib AB, El-Ghezal S, Cheikhrouhou M. 2006. A study of the impact of elastane ratio on mechanical properties of cotton wrapped elastane-core spun yarns. The Journal of the Textile Institute 97(2), 167-172.

17. Örtlek HG, Ülkü Ş. 2007. Effects of spandex and yarn counts on the properties of elastic core-spun yarns produced on Murata vortex spinner. Textile Research Journal 77(6), 432-436.

18. Das A, Chakraborty R. 2013. Studies on elastane-cotton core-spun stretch yarns and fabrics: Part I-Yarn characteristics. Indian Journal of Fibre \&Textile Research 38, 237-243.

19. Aydoğdu SH, Yılmaz D. 2019. Analyzing some of the dual-core yarn spinning parameters on yarn and various fabric properties. Tekstil ve Konfeksiyon 29(3), 197-207.

20. Baykal PD, Babaarslan O, Erol R. 2006. Prediction of strength and elongation properties of cotton/polyester-blended OE rotor yarns. Fibres \& Textiles in Eastern Europe 14, 1 (55), 18-21.

21. Qadir MB, Hussain T, Malik M, Ahmad F, Jeong SH. 2014. Effect of elastane linear density and draft ratio on the physical and mechanical properties of core-spun cotton yarns. The Journal of The Textile Institute 105 (7), 753-759.

22. Çopur M, Özmetin C, Özmetin \& Kocakerim MM. 2004. Optimization study of the leaching of roasted zinc sulphide concentrate with sulphuric acid solutions. Chemical Engineering and Processing: Process Intensification 43(8), 1007-1014.

23. Park CK, Ha JY. 2005. A process for optimizing sewing conditions to minimize seam pucker using the Taguchi Method. Textile Reseach Journal 75(3), 245-252. 